\title{
ACESSIBILIDADE E PERMANÊNCIA NO ENSINO SUPERIOR: UMA ANÁLISE SOBRE INCLUSÃO, INTERCULTURALIDADE E INOVAÇÃO PEDAGÓGICA NA UERJ E NA UFRJ
}

\author{
Accessibility and permanence in Higher Education: an analysis on inclusion, \\ interculturality and pedagogical innovation in UERJ and UFRJ
}

\section{Accesibilidad y permanencia en la Enseñanza Superior: un análisis sobre inclusión, interculturalidad e innovación pedagógica en UERJ y UFRJ}

\author{
Maicon Salvino Nunes de Almeida* \\ Fernanda Iglesias Webering** \\ Valeria de Oliveira Silva*** \\ Mayara Carvalho de Oliveira****
}

\begin{abstract}
Resumo
O Observatório Internacional de Inclusão, Interculturalidade e Inovação pedagógica (OIIIIPe), pertencente ao Laboratório de Pesquisas, Estudos e Apoio à Participação e à Diversidade em Educação (LaPeade/FE/UFRJ), vem construindo uma rede de colaboração que conta, atualmente, com universidades do Brasil e de outros países. Neste artigo, efetuamos um recorte acerca das culturas, políticas e práticas de inclusão (BOOTH; AINSCOW, 2011), interculturalidade e inovação pedagógica presentes na Coordenadoria de Avaliação, Projetos Especiais e Inovação (Copei-UERJ), na Coordenação do Programa de Iniciação Acadêmica (Proiniciar-UERJ) e no Fórum Permanente UFRJ Acessível e Inclusiva (UFRJ). Para tanto, foi realizado levantamento bibliográfico, a fim de conhecermos o estado da arte das produções existentes sobre tais temáticas, bem como análise documental do Regimento do Fórum Permanente UFRJ Acessível e Inclusiva. A coleta de dados se deu por meio de entrevistas realizadas com a presidente do Fórum e com a coordenadora da Copei, de modo que os dados analisados auxiliaram na compreensão das práticas existentes e em construção, no que tange à inclusão, interculturalidade e inovação pedagógica nas duas instituições de Ensino Superior pesquisadas.
\end{abstract}

PALAVRAS-CHAVE: Inclusão. Interculturalidade. Inovação pedagógica. Acessibilidade. Polìticas públicas.

\footnotetext{
* Mestrando do Programa de Pós-Graduação da Faculdade de Educação da Universidade Federal do Rio de Janeiro. Membro do LaPeade (Laboratório de Pesquisa, Estudos e Apoio à Participação e à Diversidade em Educação, do Programa de Pós-Graduação da Faculdade de Educação/UFRJ).E-mail: >maiconsalvino@gmail.com>

** Mestranda do Programa de Pós-Graduação da Faculdade de Educação da Universidade Federal do Rio de Janeiro. Membro do LaPeade (Laboratório de Pesquisa, Estudos e Apoio à Participação e à Diversidade em Educação, do Programa de Pós-Graduação da Faculdade de Educação/UFRJ). Professora da Educação Básica da rede estadual do Rio de Janeiro. E-mail: <profernanda.letras@gmail.com>

*** Mestre em Educação (ProPEd/UERJ). Membro Colaboradora do LaPeade (Laboratório de Pesquisa, Estudos e Apoio à Participação e à Diversidade em Educação, do Programa de Pós-Graduação da Faculdade de Educação/UFRJ). Professora Assistente da Universidade do Estado do Rio de Janeiro/UERJ. Docente do Atendimento Educacional Especializado - Ensino Colaborativo (AEE-EC) do Instituto de Aplicação Fernando Rodrigues da Silveira (CAp-UERJ). Coordenadora Pedagógica do Programa Rompendo Barreiras: Luta pela Inclusão/Faculdade de Educação - UERJ. E-mail: <valeriagpdoc@gmail.com>

**** Licenciada em Letras - Português/Espanhol pela Universidade Federal do Rio de Janeiro. Mestranda em Educação pela Universidade Federal do Rio de Janeiro e membro do Laboratório de Pesquisa, Estudos e Apoio à Participação e à Diversidade em Educação (LaPeade/FE/UFRJ). E-mail: <mayoliveira_05@yahoo.com.br>
} 


\begin{abstract}
The International Observatory of Inclusion, Interculturality and Pedagogic Innovation (IOIIPI), which belongs to the Laboratory for Research, Studies and Support for Participation and Diversity in Education (LaPeade/FE/UFRJ), has been building a collaboration network of which universities from Brazil and other countries are part. In this article, we present a review of the cultures, policies and practices of inclusion (BOOTH; AINSCOW, 2011), interculturality and pedagogical innovation present in the Coordination of Evaluation, Special Projects and Innovation (Cespi-UERJ), in the Coordination of the Academic Initiation Program (Acinpro UERJ) and at the Permanent UFRJ Accessible and Inclusive Forum (UFRJ). To accomplish that, a bibliographical survey was carried out in order to know the state of the art of the existing productions about these themes, as well as documentary analysis of the Permanent UFRJ Accessible and Inclusive Forum statute. Data collection was conducted through interviews with the Forum's president and with the coordinator of COPEI, so that the data analyzed helped to understand the practices and in construction, regarding inclusion, interculturality and pedagogical innovation in the two Higher Education institutions surveyed.
\end{abstract}

KEYWORDS: Inclusion. Interculturality. Pedagogical innovation. Accessibility. Public policy.

\title{
Resumen
}

El Observatorio Internacional de Inclusión, Interculturalidad e Innovación pedagógica (OIIIIPe), perteneciente al Laboratorio de Investigaciones, Estudios y Apoyo a la Participación y la Diversidad en Educación (LaPeade/FE/UFRJ), viene construyendo una red de colaboración que cuenta actualmente universidades de Brasil y de otros países. En este artículo, efectuamos un recorte acerca de las culturas, políticas y prácticas de inclusión (BOOTH; AINSCOW, 2011), interculturalidad e innovación pedagógica presentes en la Coordinadora de Evaluación, Proyectos Especiales e Innovación (COPEIUERJ), en la Coordinación del Programa de Iniciación Académica (Proiniciar UERJ) y en el Foro Permanente UFRJ Accesible (UFRJ). Para ello, se realizó un levantamiento bibliográfico, para conocer las producciones existentes sobre tales temáticas, así como análisis documental del Reglamento del Foro Permanente UFRJ Accesible e Inclusiva. La recolección de datos se dio a través de entrevistas realizadas con la presidenta del Foro y con la coordinadora de la Copei, de manera que los datos analizados ayudaron en la comprensión de las prácticas existentes y en construcción, en lo que se refiere a la inclusión, la interculturalidad e innovación pedagógica dos instituciones de Enseñanza Superior investigadas.

PALABRAS CLAVE: Inclusión. Interculturalidad. Innovación pedagógica. Accesibilidad. Políticas públicas

\section{INTRODUÇÃO}

O Observatório Internacional de Inclusão, Interculturalidade e Inovação Pedagógica (OIIIIPe) conta com a participação de cerca de 100 pesquisadores, de 23 Instituições de Ensino Superior (IES) brasileiras e estrangeiras. Trata-se de uma rede de colaboração que vem sendo desenvolvida desde 2015, cujo objetivo é

[...] investigar contradições e perspectivas emergentes em propostas e experiências de inclusão, interculturalidade e inovação pedagógica desenvolvidas no processo de 
formação de educadores em universidades nacionais e internacionais, por meio de variadas metodologias e subprojetos de pesquisa. ${ }^{1}$

Por se trata de uma pesquisa de abrangência internacional, foi acordada, entre os pesquisadores, a necessidade de uma equipe coordenadora do projeto, responsável pelo planejamento e desenvolvimento das reuniões mensais de pesquisa, bem como pelas demais atividades inerentes ao trabalho colaborativo realizado pelo Observatório. Atualmente, a coordenação é formada pela equipe do Rio de Janeiro, a qual compreende a Universidade Federal Fluminense (UFF), a Universidade Federal do Rio de Janeiro (UFRJ) e a Universidade do Estado do Rio de Janeiro (UERJ), sendo estas duas últimas objeto deste artigo.

A Universidade do Estado do Rio de Janeiro (UERJ) é considerada a primeira universidade do Brasil a adotar a política de reserva de vagas. Estudos realizados em 2012 pela Coordenadoria de Articulação e Iniciação Acadêmicas (Caiac), subordinada à Sub-reitoria de Graduação, revelam que, entre o ano de 2003 e o primeiro semestre de 2012, dos 47.540 estudantes que ingressaram na UERJ, 15.935 ocuparam as vagas reservadas a negros (6.995), a candidatos oriundos da rede pública (8.673) e aos que apresentavam alguma deficiência, indígenas ou filhos de policiais, bombeiros e inspetores de segurança mortos ou incapacitados em serviço (267).

Esse quantitativo corresponde a $34 \%$ dos estudantes de graduação nesse período. Com relação ao número de concluintes, registrou-se um total de 6.869 estudantes, $22 \%$ dos que concluíram os cursos de graduação. A análise assinala, ainda, que o percentual de evasão entre os alunos ocupantes das vagas reservadas a grupos específicos é menor do que entre os demais estudantes, 20\% contra 33\% (UERJ, 2013). Atualmente, a reserva de vagas é um dos mecanismos de promoção da inclusão em outras instituições públicas de ensino superior em todo o Brasil.

A Universidade Federal do Rio Janeiro, por sua vez, há alguns anos, já se preocupava em estabelecer medidas que diminuíssem as exclusões e facilitassem o acesso e a permanência dos estudantes com deficiência na universidade. Em 2007, foi criado o Núcleo Interdisciplinar de Acessibilidade (NIA) e a instituição passou a fazer parte do Incluir - programa de acessibilidade no Ensino Superior que consistia em uma política pública, proposta pelo governo federal, cujo objetivo era integrar iniciativas isoladas, provenientes de diferentes faculdades, de modo a ampliar a acessibilidade para as pessoas com deficiência.

Em 2010, o NIA foi incorporado pela então criada Divisão de Inclusão Social, Acessibilidade e Assuntos Comunitários (Dinaac), que visa propor normas, adaptações nos prédios, fiscalização das ações realizadas e, também, iniciativas para melhorar a qualidade de vida do estudante. Entretanto, as ações relativas à acessibilidade e às pessoas com deficiência continuaram sendo muito pontuais, por uma série de motivos, entre os quais destacamos a falta de orçamento suficiente e de pessoal. Nesse contexto, e no intuito de continuar tentando articular as várias ações isoladas de Núcleos e Laboratórios de pesquisa que tratam o tema da acessibilidade, ocorreu o primeiro Fórum Universitário de Acessibilidade, em abril de 2013, o qual conseguiu consolidar uma rede de profissionais da UFRJ que já trabalhavam com o tema, dando origem, em 2016, ao Fórum Permanente UFRJ Acessível e Inclusiva.

Diante do exposto, apresentaremos algumas práticas desenvolvidas em prol da inclusão, interculturalidade e inovação pedagógica na UFRJ e na UERJ, a partir da análise de ações

\footnotetext{
${ }^{1}$ Referência retirada do projeto de pesquisa intitulado "Formação de educadores: inclusão, interculturalidade e inovação pedagógica em contextos internacionais de ensino superior", em desenvolvimento, desde 2015, pelo Observatório Internacional de Inclusão, Interculturalidade e Inovação Pedagógica (OIIIIPe).
} 
promovidas por programas como o Programa de Iniciação Acadêmica (Proiniciar-UERJ), a Coordenadoria de Avaliação, Projetos Especiais e Inovação (Copei-UERJ), que desenvolve o Projeto UERJ Acessível, ${ }^{2}$ e o Fórum Permanente UFRJ Acessível e Inclusiva.

\section{Inclusão em educação: a perspectiva que defendemos}

Entende-se inclusão em educação como um processo de democratização da escola com o objetivo de diminuir as exclusões, agregando pessoas e reconhecendo a existência das diferenças. Inclusão está, portanto, baseada no acesso, permanência e participação do indivíduo. Segundo Sawaia (2001), só existe a inclusão porque há exclusões. Para a autora, a inclusão pode ser perversa porque uma pessoa pode ter acesso e permanência na escola, mas, se ela não participa, não houve a inclusão.

Ao falar sobre o tema, Booth e Ainscow (2000) estabelecem três dimensões que devem ser praticadas até se chegar à inclusão. A primeira é desenvolvendo culturas. Tem a ver com a apropriação dos valores para a inclusão na cultura das pessoas; no caso da comunidade universitária, refere-se à mudança nos hábitos. De acordo com os autores, os valores para a inclusão são a participação, a igualdade, a não violência, direitos, compaixão, amizade, comunidade, respeito à diversidade, sustentabilidade, coragem, confiança, honestidade, alegria, beleza e amor. Todos os valores devem ser dominados e desenvolvidos por meio da participação efetiva de cada membro. Dessa forma, podem-se evitar a discriminação, a hegemonia cultural e valorizar o reconhecimento das diferenças.

A segunda dimensão, produzindo políticas, tem o objetivo de orientar as ações, são as diretrizes, normas e portarias, formalidades que sirvam como base para se desenvolver um ambiente universitário em que todos participam e apoiam a diversidade. Também há uma relação bastante estreita com o planejamento para que se tenha continuidade na ação de determinada política.

Com relação à última dimensão, trata-se das ações propriamente ditas, tanto dos estudantes quanto dos professores, responsáveis pela gestão, funcionários de apoio, todos os que compõem a comunidade universitária.

De acordo com Santos (2015), a inclusão é um processo ininterrupto, contínuo, que tem o objetivo principal de minimizar as exclusões mediante, principalmente, a participação das pessoas. Segundo a autora, "é um processo que precisa ser compreendido de uma forma totalizante, tendo em vista que abrange de modo tanto complexo quanto dialético, o desenvolvimento de culturas, políticas e práticas de inclusão entre e pelos atores e instituições educacionais" (SANTOS, 2015, p. 487).

Nesse contexto, pode-se observar o movimento das três dimensões citadas anteriormente: quando se fala em educar a comunidade para a nova realidade, está-se referindo a uma mudança nas culturas; a criação do fórum relaciona-se com as políticas e todas as ações envolvidas têm a ver com as práticas. Portanto, há um trabalho transformador em prol da inclusão em educação.

\footnotetext{
2 Trata-se de um programa cujo objetivo é mapear o quantitativo de graduandos com deficiência na UERJ, de modo a possibilitar que a universidade tenha condições de promover plenas acessibilidade e inclusão desse alunado, atendendo-os em suas demandas. Informação disponível em: <http://www.copei.uerj.br/projetos/uerjacessivel>.
} 


\title{
O processo de inclusão nos cursos de graduação da UERJ
}

A inclusão nos cursos de graduação na UERJ vem sendo construída há alguns anos com um olhar plural e trabalhada de forma a garantir o respeito às diferenças. O Programa de Iniciação Acadêmica (Proiniciar-UERJ), criado há mais de dez anos em função da reserva de vagas, vem dando suporte aos estudantes que necessitam de apoio pedagógico, oferecendo nivelamento e práticas extracurriculares.

Com a atuação do Proiniciar, os estudantes têm acesso a cursos e oficinas, atividades culturais e artísticas. As atividades podem ser específicas de cada curso e/ou mais abrangente. Ele oferece Língua Portuguesa, Línguas Estrangeiras, laboratórios, fotografias, dança, música. Realizadas dentro da Universidade, essas atividades são disponibilizadas pelas unidades de forma gratuita, sem qualquer custo para o aluno, inclusive as proporcionadas por outros profissionais, como a oficina de yoga.

Os graduandos acompanhados pelo Programa buscam os cursos e as oficinas como forma de agregar mais conhecimento, além da participação em atividades às quais muitos ainda não tiveram acesso, inclusive por falta, em seu cotidiano, de condições de participar.

No tocante às práticas de formação de professores para inclusão, segundo a Professora Celly Saba, coordenadora da Coordenadoria de Avaliação, Projetos Especiais e Inovação (Copei-UERJ), dentre aquelas desenvolvidas pelas licenciaturas no sentido de melhorar a inclusão, é possível citar a disciplina de Língua Brasileira de Sinais (Libras), oferecida principalmente aos cursos de licenciaturas pelas Faculdades de Letras e de Educação. Destacase também o cumprimento da Resolução $n .^{\circ} 02 / 2015$, que determina a reformulação de todas as licenciaturas com a inclusão de disciplinas e práticas que tenham como objetivo versar sobre inclusão.

A esse respeito, Santos (2013, p. 109) acrescenta que o "processo de inclusão em educação está fortemente vinculado à participação, que significa aprender junto com os outros, ampliando experiências e, sobretudo, exercendo a capacidade de decisão e progressiva autonomia". Vale ressaltar que, desde 2003, a Faculdade de Educação oferece às Licenciaturas e ao curso de Pedagogia duas disciplinas sobre a educação de pessoas com deficiência - Prática em Educação Inclusiva e Questões Atuais em Educação Especial/Educação Inclusiva e Cotidiano escolar. Além dessas disciplinas, a Faculdade de Educação disponibiliza estágios regulares em movimentos sociais. Bolsas de iniciação científica, extensão e iniciação à docência em projetos cujo objetivo é tratar de questões sobre pessoas com deficiência, negros, gênero e outras também são concedidas.

De acordo com a autora,

\begin{abstract}
Por mais que inclusão seja processo, é preciso lembrar que ela é um processo em direção à garantia de um direito humano básico e inalienável. Este direito não tem como ser cumprido por meio da separação de pessoas, mas somente com a convivência pessoal, escolar, acadêmica, social e cultural de pessoas (SANTOS, 2012, p. 7).
\end{abstract}

Outro projeto gerenciado pela Copei é o UERJ acessível, o qual deve acompanhar estudantes que apresentem alguma demanda e/ou necessidades acadêmicas especiais. A identificação desses graduandos é feita a partir de um formulário informativo acessado pelo sistema online de matrícula. Entretanto, caso algum discente apresente queixas específicas, a Copei se prontifica a acompanhá-lo. Dentre as parcerias firmadas com o UERJ Acessível destaca-se o Programa Rompendo Barreiras: Luta pela Inclusão, da Faculdade de Educação, 
que desenvolve onze projetos específicos destinados à adequação curricular e ao desenvolvimento de práticas pedagógicas cujo princípio é a acessibilidade, pois, sem acessibilidade, não há inclusão.

\section{Como vem sendo trabalhada a inclusão no fórum permanente UFRJ acessível e inclusiva?}

A Lei n. ${ }^{\circ}$ 12.711, de 29 de agosto de 2012, que delibera a abertura de vagas de ações afirmativas para pretos, pardos, indígenas, pessoas de baixa renda e alunos que tenham cursado o ensino fundamental integralmente em escolas públicas, foi alterada em 28 de dezembro de 2016 pela Lei n. ${ }^{\circ}$ 13.409, determinando a reserva de vagas também para pessoas com deficiência. Portanto, o Fórum UFRJ Acessível e Inclusiva tem um papel muito importante, pois serve como base de apoio para a comunidade universitária lidar com a nova situação.

O Fórum possui um regimento próprio, "sendo um espaço regular de discussão, elaboração e suporte ao desenvolvimento e implementação da política institucional em acessibilidade", ${ }^{3}$ cujo objetivo é estabelecer políticas estratégicas para o fortalecimento da acessibilidade, realizar debates e reflexões sobre ações que incluam as pessoas com deficiência, vincular os coordenadores de projetos que envolvam inclusão com o fórum, dialogar com outras instituições, buscar mais recursos para fomentar pesquisas sobre acessibilidade, aumentar o ensino e pesquisa na área (REGIMENTO DO FÓRUM, 2017).

Em entrevista concedida para a produção deste artigo, no dia 17 de janeiro de 2018, Mônica Pereira dos Santos, professora associada da Faculdade de Educação e presidente da Comissão Executiva do Fórum, fala um pouco sobre o conceito de inclusão no Fórum. Nesta entrevista, a presidente explicitou qual é o enfoque de inclusão utilizado no Fórum, assim como algumas ações realizadas e algumas políticas em desenvolvimento. $\mathrm{O}$ objetivo dessa entrevista foi compreender como o Fórum está desenvolvendo suas culturas, políticas e práticas com enfoque na inclusão.

Existem algumas perspectivas em disputa dentro do fórum temos aqueles que defendem que inclusão está vinculada mais à deficiência, há outros que defendem, como eu, que inclusão é pra todos, mas como o fórum tem como foco específico as pessoas com deficiência, a visão de inclusão que predomina é essa das pessoas com deficiência e as ações têm sido, portanto, centradas em torno da acessibilidade. Esse é o tema central do Fórum, mais até do que de inclusão, na pressuposição de que ao se trabalhar a acessibilidade trabalhar-se-ia a inclusão.

A professora também detalhou que ações estão sendo feitas, a saber:

Por meio de ações de conscientização a cada semestre, com eventos de acolhimento aos novos estudantes, funcionários e professores, com duração de dois ou três dias, e ele é bem prático, quase uma oficina, em que se diz que tipo de coisas as pessoas com deficiência gostam ou não, que tipos de adaptações simples podem ser feitas, o que a gente precisa entender para lidar com essas pessoas no dia a dia, também estamos pensando em elaborar uma cartilha, muitas parcerias.

Ainda de acordo com a presidente,

\footnotetext{
3 Trecho retirado do Regimento do Fórum Permanente UFRJ Acessível e Inclusiva. Disponível em: <https://ufrj.br/sites/default/files/documentos/2016/09/regimento_concluido_2.pdf>.
} 


\begin{abstract}
A intenção é tentar educar a comunidade para essa nova realidade. Há muito trabalho político para se estabelecer uma rede de parcerias com o reitor, pró-reitores, decanos, diretores de Unidades, tentar orientar as dúvidas dos que procuram o fórum, pois também há um movimento dos próprios institutos para a solução de problemas. Além disso, estamos elaborando um banco de dados para se conhecer melhor esse público.
\end{abstract}

Diante do exposto, pode-se observar o movimento das três dimensões que se relacionam de forma complexa e dialética: ao se modificarem os hábitos, há uma relação com as culturas, pois é primordial que se deixem de lado costumes excludentes; quando se criam um regimento próprio e uma presidência, pode-se constatar a presença de políticas; por fim, as práticas referem-se à ação propriamente dita. Portanto, pode-se evidenciar o processo de inclusão.

\title{
O conceito de interculturalidade e seu desenvolvimento no FÓRUM permanente UFRJ acessível e inclusiva
}

O conceito de interculturalidade, na concepção de Fleuri (2003), é utilizado para explicar fatores incongruentes entre si, mas que convivem juntos. Um trabalho intercultural tem a ver, portanto, com uma mudança de olhar, respeitando a diferença. Segundo o autor:

\footnotetext{
A educação intercultural no contexto das lutas sociais contra os processos crescentes de exclusão social inerentes à globalização econômica propõe o desenvolvimento de estratégias que promovam a construção de identidades particulares e o reconhecimento das diferenças, ao mesmo tempo em que sustentem a inter-relação crítica e solidária entre diferentes grupos (FLEURI, 2001, p. 1).
}

De acordo com Candau (2012), os termos multiculturalismo e interculturalidade são tratados, por alguns autores, como sinônimos. Para outros, são termos que se contrapõem: multiculturalismo refere-se aos grupos culturais reafirmados nas suas diferenças, sem interação ou influência mútua; por interculturalidade, as inter-relações entre diferentes grupos culturais. A autora trabalha sob a perspectiva de um multiculturalismo aberto e interativo, que acentua a interculturalidade, por considerá-la mais adequada para a construção de sociedades, democráticas e inclusivas, que articulem políticas de igualdade com políticas de identidade e reconhecimento de diferentes grupos culturais. Sendo assim, a autora se baseia no conceito de interculturalidade crítica.

Ainda, segundo Santos (2015), interculturalidade pode ser compreendida como:

\begin{abstract}
Um campo de reflexão, conhecimentos e práticas que implicam ações intencionais, voltadas para o desenvolvimento da alteridade, da construção da justiça social, da garantia de direitos e da consideração e respeito aos aspectos subjetivos e identitários, das diferentes posições pessoais e culturais que assumimos cotidianamente, em nossos diferentes papéis da vida humana e social. Em assim sendo, podemos dizer que a interculturalidade é, também, demarcada por uma multidimensionalidade, na medida em que precisa levar em conta pessoas, subjetividades, grupos sociais, culturas, políticas, ideologias, religiões, línguas, etnias, relações de gênero e afins, histórias, alimentação, vestimentas, preconceitos, expectativas [...] (SANTOS, 2015, p. 63).
\end{abstract}

A importância de discutir a inclusão de pessoas de diferentes culturas que se inserem na universidade brasileira, por exemplo, os estudantes refugiados que ingressam na UFRJ, é tema de interesse do Fórum UFRJ Acessível e Inclusiva. Todavia, encontramos na Universidade Federal do Rio de Janeiro um cenário em construção ainda embrionário, no 
tocante à discussão da interculturalidade e a necessidade de reafirmá-la por meio de políticas e práticas inclusivas. Nas palavras da presidente do Fórum Permanente UFRJ Acessível e Inclusiva, "As coisas ainda são um pouco nebulosas [...] no que tange à interculturalidade, nem se fala isso no fórum ainda. Acho que a gente vai chegar lá".

Apesar desse contexto introdutório, a fim de proporcionar um ambiente mais inclusivo, práticas inclusivas provenientes da interação entre diferentes culturas no âmbito universitário são percebidas e discutidas na UFRJ, segundo o Pró-Reitor da UFRJ, Agnaldo Fernandes:

\begin{abstract}
Eu sei de um caso específico, esse passou por mim aqui, que é um sírio, que veio com a família e está fazendo engenharia com a gente e aí teve todo o envolvimento da PróReitoria de graduação com a coordenadora do curso lá da poli e, então nesse sentido, temos, a universidade tem sido sensível a esse tema (estudantes refugiados), talvez não na abrangência e na profundidade que o caso requeira, mas já há alguma movimentação em relação a isso. No CEG e me parece que na pós-graduação também tem, não temos tido problema quanto a isso. Na medida em que surge, a gente vai dando conta de tratar, dentro das limitações que a universidade tem tido por hora (FERNANDES, 2017).
\end{abstract}

Essas práticas inclusivas para pessoas de diferentes culturas existem no ambiente universitário da UFRJ, sem uma política institucionalizada. Dessarte, o Fórum UFRJ Acessível e Inclusiva caminha a passos curtos quanto à inclusão de pessoas de diferentes culturas, mas as práticas citadas pelo Pró-Reitor explicitam que, apesar da ausência de legislação, os casos que surgem na universidade não são tratados de forma omissa, reforçando que a necessidade de inclusão não é somente um movimento voltado para pessoas com deficiência.

A discussão sobre a inclusão escolar ultrapassa, assim, o âmbito da Educação Especial, pois ao pensar uma escola para todos questiona-se a própria constituição das interações nesse espaço e nas relações da sociedade como um todo (LAGO; SANTOS, 2011, p. 3).

Portanto, faz-se necessário um olhar mais atento à questão da interculturalidade, pois com os constantes fluxos migratórios a universidade precisa se preparar para receber pessoas de culturas diversas para realizar a práxis intercultural. Isso porque a resistência às diferenças, no âmbito do ensino superior, é uma problemática que muitos acreditam não existir, ou fecham os olhos à sua existência, mas que está presente em todas as arenas sociais.

$\mathrm{Na}$ UERJ, a prática da interculturalidade aparece explicitada em um projeto desenvolvido pela Copei, destinado a estudantes de graduação oriundos de países em desenvolvimento. A participação da UERJ no PEC-G - Programa de Estudantes-Convênio de Graduação: programa de intercâmbio acadêmico administrado pelo DCI - Departamento de Intercâmbio da Universidade - também revela práticas interculturais. Pelo PEC-G, a Universidade recebe estudantes em intercâmbio para serem diplomados pela UERJ. São graduandos selecionados em seu país de origem sem qualquer interferência da universidade. Por esse motivo, idade, sexo e nível de conhecimento somente são conhecidos no ato da apresentação à universidade. O objetivo de cada estudante é graduar-se e retornar para melhor contribuir com a infraestrutura de seu país.

O PEC-G é um programa oferecido a países da América do Sul, América Central e África. Esses países apresentam sua demanda e solicitam, em geral, vagas para os cursos de Pedagogia, Licenciaturas, Enfermagem, Medicina, Engenharias e Direito (DAVID; REGIS, 2014, p. 2). O DCI e a Copei recebem as demandas e a Copei gerencia a distribuição das vagas, 
encaminhando a documentação necessária ao Ministério das Relações Exteriores. Os estudantes não oriundos de países lusófonos, durante um ano, fazem um curso de Português oferecido pela UFRJ em parceria com a UFF, e somente aqueles que passam na prova de proficiência de Língua Portuguesa são matriculados nas graduações.

\section{O conceito de inovação pedagógica e sua articulação com o FÓRUM permanente UFRJ acessível e inclusiva e com os programas da UERJ}

Embora muitos considerem que inovar seja trocar um instrumento por outro, um dispositivo obsoleto por um de última geração, entendemos que inovar, em educação, é perceber que não existe um único currículo, que não se devem praticar formas cristalizadas de avaliação, que as culturas coletivas e individuais se afetam e, também, interferem (ou deveriam interferir) nos currículos aplicados nas escolas e universidades; é necessário desenvolver um olhar capaz de detectar particularidades e necessidades educacionais ímpares.

Inovamos quando quebramos paradigmas, quando entendemos, por exemplo, que particularidades de uma língua materna, diferente da utilizada nos textos acadêmicos, podem interferir na produção do graduando. Tanto um estudante com surdez quanto um nativo de um país que não tenha a Língua Portuguesa como língua oficial poderão encontrar dificuldades para se expressar por escrito. No entanto, se o docente está atento a esses detalhes, podemos dizer que esse professor tem uma postura inovadora.

Nesse sentido,

Entendemos que a inovação requer uma ruptura necessária que permita reconfigurar o conhecimento para além das regularidades propostas pela modernidade. Ela pressupõe, pois, uma ruptura paradigmática, e não apenas a inclusão de novidades, inclusive as tecnológicas. Nesse sentido, envolve uma mudança na forma de entender o conhecimento (CUNHA, 2008, p. 22-23).

Como forma de ruptura de um assunto/conhecimento pouco abordado na UFRJ, o Fórum Permanente UFRJ Acessível e Inclusiva surge em um momento em que se torna necessária a discussão dos conteúdos trabalhados em sala de aula na universidade, com o intuito de promover um espaço acadêmico que inove em sua prática, pois do contrário recairá sobre o aluno com necessidades especiais a responsabilidade de adequar-se à universidade. Nesse sentido, não é o aluno que deve se adaptar à universidade, mas sim a universidade que tem por obrigação adaptar-se ao discente.

Dentro do Fórum UFRJ Acessível e Inclusiva algumas práticas de inovação pedagógica são perceptíveis e apontadas pela presidente da Comissão Executiva do Fórum, Mônica Pereira dos Santos, a qual nos explica, em entrevista:

E no que tange à inovação pedagógica a discussão fica mais em torno mesmo de recursos digitais, de tecnologia assistiva, pedagógico-didáticos que se possam desenvolver em sala de aula e no dia a dia das relações sociais para o trato com as pessoas com deficiência. É nesse sentido, mas, então assim, não tem grandes inovações no sentido de uma quebra de paradigmas, mas há muita criação. Acho que a grande inovação é tentar mostrar para as pessoas da UFRJ que existem inovações possíveis de serem feitas. Nós estamos num momento muito inicial, muito incipiente ainda, de educar essa comunidade, e isso em si já é um trabalhão. 
A iniciativa de inovação pedagógica existente nesse momento no Fórum é a criação de um banco de dados com o objetivo de mapear os estudantes com deficiência, de modo a criar estratégias para atendê-los. A presidente da Comissão Executiva do Fórum argumentou em entrevista que:

Uma outra ação que tem a ver com inclusão e poderá ajudar futuramente na inovação
pedagógica e também na compreensão desses aspectos em relação à interculturalidade
é banco de dados. A gente está tentando construir, agora nas matrículas de $2018 / 1$, a
gente vai se esforçar para conseguir que pelo menos os alunos entrantes sejam
cadastrados com uma certa precisão, para a gente ter o mínimo de ideia das suas
necessidades e o que as unidades poderão/deverão fazer para facilitar a vida e o
convívio com
comosses

Espera-se que esse banco de dados auxilie no atendimento a esses estudantes com deficiência, para que eles possam expressar suas potencialidades e limitações diante das dificuldades que a universidade ainda possui para atendê-los. Esse banco de dados ainda está em processo de criação, o que não nos permite dizer suas estratégias e metodologias, pois, $a$ priori, ainda está em fase embrionária.

A UERJ, por sua vez, inova quando apresenta propostas de avaliações mais inclusivas, especialmente em seu vestibular e avaliações de acesso ao seu colégio de aplicação - CAPUERJ e currículos abertos à construção coletiva com a participação discente. No que concerne ao uso de dispositivos eletrônicos e móveis, conectados ou não em rede, se podem substituir ou complementar algum dos sentidos (visão, audição ou movimento motor), são equipamentos que buscam proporcionar uma educação mais inclusiva. Tais dispositivos também podem auxiliar quem apresenta dificuldades linguísticas. No Programa Rompendo Barreiras (PRB-UERJ), materiais impressos, imagens, tabelas, gráficos e materiais acadêmicos com outras configurações são vertidos em textos digitais, os quais podem ser acessados por estudantes com dislexia, baixa visão ou com cegueira.

Apesar das formas inovadoras de troca de conhecimentos na UERJ, entendemos que muitas das práticas deveriam ser mais discutidas, pois, ainda estão no campo do individual; colaborar, compartilhar e incentivar a troca de conhecimentos é necessário. No que diz respeito às tecnologias e inovações, pelo que já foi dito até aqui, consideramos que é possível contribuir, inclusive, para se estabelecerem formas de se fazer pesquisa e formar professores que construam cotidianamente novas práticas docentes, com princípios éticos e culturais a partir de práticas de inclusão, com a valorização da interculturalidade com uma visão multirreferencial (MACEDO, 2011).

\section{CONSIDERAÇÕES FINAIS}

Apesar de um tímido avanço, o Fórum UFRJ Acessível e Inclusiva revelou progressos nas temáticas interculturalidade, inovação pedagógica e inclusão, sendo este último o campo com maior avanço, em razão da demanda dos estudantes negros, indígenas e com deficiências que ingressam via Enem e precisam ser incluídos na universidade em 2018. Diferente da UERJ que, devido à sua tradição na reserva de vagas, além da inclusão de estudantes com deficiência, recebe em seu quadro discente, por meio de seu vestibular, entre outros, estudantes negros e oriundos de escolas públicas. 
Não há dúvidas de que o Fórum Permanente UFRJ Acessível e Inclusiva desponta em um momento em que a universidade precisa articular-se para receber uma grande demanda de estudantes com deficiência e somente agora, por esse motivo, que a UFRJ se mobilizou. A crítica maior neste artigo está na ausência, até o presente Fórum UFRJ Acessível e Inclusiva, por parte da universidade, de discussão de políticas e práticas para os estudantes com deficiência que já estão na universidade há longas décadas sofrendo por falta de estrutura e planejamento da instituição.

A UERJ apresenta registros e resultados das discussões sobre inclusão desde 1988, quando foi criado o Programa Rompendo Barreiras: Luta pela Inclusão. Ao longo desses 30 anos, projetos e programas foram institucionalizados buscando a inclusão de todos, trocas culturais novas práticas

pedagógicas.

Outra crítica está na discussão da interculturalidade. No Fórum Permanente UFRJ Acessível e Inclusiva não se identifica esse debate. Em futuros trabalhos, aprofundaremos a necessidade da universidade de discutir e preparar um espaço inclusivo para a interculturalidade, pensando nos estudantes que já estão na universidade e para que, caso haja um grande fluxo migratório para o Brasil, os estudantes oriundos de outros países não sofram em virtude da ausência de políticas públicas.

\section{REFERÊNCIAS}

BRASIL, Ministério da Educação. Estudante com deficiência terá cota nas instituições federais. Ministério da Educação. Disponível em $<$ http://portal.mec.gov.br/ultimasnoticias/202-264937351/43701-estudante-com-deficienciatera-cota-nas-instituicoesfederais $\rangle$. Acesso em: $\langle 15 / 01 / 2018\rangle$.

BOOTH, T.; AINSCOW, M. Index para a inclusão: desenvolvendo a aprendizagem e a participação na escola. Produzido pelo Laboratório de Pesquisa, Estudos e Apoio à Participação e à Diversidade em Educação - LaPEADE, FE-UFRJ. Tradução de Mônica Pereira dos Santos. 3. ed. Rio de Janeiro: Unesco/CSIE, 2000.

CANDAU, Vera Maria. Diferenças culturais, interculturalidade e educação em direitos humanos. Educação e Sociedade, v. 33, jan.-mar. 2012.

CUNHA, M. I. Nos caminhos da pesquisa. Inovações pedagógicas: o desafio da reconfiguração de saberes na docência universitária. USP, Cadernos Pedagogia Universitária, 2008.

FLEURI, R. M. Desafios à educação intercultural no Brasil. Revista Educação, Sociedade e Cultura, n. 16, p. 45-62, 2001. Disponível em: <http://www.fpce.up.pt/ciie/revistaesc/ESC16/16-2.pdf>. Acesso em: <23 jan. 2018>.

FLEURY, Reinaldo Matias. Intercultura e educação. Revista Brasileira de Educação, Rio de Janeiro, n. 23, p. 16 - 35, 2003. 
DAVID, H. C. S.; REGIS, C. V. Os alunos PEC-G na graduação da UERJ: acesso e permanência no ensino superior. In: XVII ENCONTRO NACIONAL DE DIDÁTICA E PRÁTICA DE ENSINO. Caderno de Resumos do XVII ENDIPE, Fortaleza: EdUECE, 2014. volume único, p. 10-528.

LAGO, M.; SANTOS, M. Inclusão em educação: desafios da formação docente. III Seminário de Educação Brasileira, Campinas, 28 de fevereiro, 1 e 2 de março de 2011.

MACEDO, R. S. Atos de currículo formação em atos? Para compreender, entretecer e problematizar currículo e formação. Ilhéus: Editus, 2011.

SANTOS, Mônica Pereira dos. Políticas públicas de inclusão de pessoas com deficiência: uma análise omnilética. XVI ENDIPE - Encontro Nacional de Didática e Práticas de Ensino Unicamp. Campinas, 2012.

SANTOS, Mônica Pereira dos. Dialogando sobre inclusão em educação: contando casos (e descasos). Curitiba: CRV, 2013.

SANTOS, Mônica Pereira dos. Rede internacional de inclusão em educação: culturas, políticas e práticas de inclusão/exclusão em educação. Projeto de Pesquisa. Laboratório de Pesquisa, Estudos e Apoio à Participação e à Diversidade em Educação. Rio de Janeiro: Faculdade de Educação/UFRJ, 2014a.

SANTOS, Mônica Pereira dos. O index para a inclusão como instrumento de pesquisa: uma análise crítica. Revista Brasileira de Educação, v. 20, n. 4, out.- dez. 2014b.

SANTOS, Mônica Pereira dos. Inclusão, direitos humanos e interculturalidade: uma tessitura omnilética. Inovação, ciência e tecnologia: desafios e perspectivas na contemporaneidade. Campina Grande: Realize, 2015.

SANTOS, Mônica Pereira dos. SANTIAGO M. C.; MELO, S. C. Formação de professores para o atendimento educacional especializado: políticas e práticas instituintes de inclusão. III Encontro do Observatório Nacional de Educação Especial (III EONEESP), jun. 2015. Disponível em: <http://www.lapeade.com.br/publicacoes/artigos/Artigo\%20Revista\%20Aleph.pdf >. Acesso $\begin{array}{lll}\text { em: } & <23 & \text { jan. }\end{array}$

SAWAIA, B. et al. As artimanhas da exclusão: análise psicossocial e ética da desigualdade social. 2. ed. Petrópolis: Vozes, 2001. 
SOUZA, A. C. S. Sistema de cotas na UERJ: uma abordagem sobre a demanda de inscritos. Revista Eletrônica do Vestibular UERJ. Disponível em: $<$ http://www.revista.vestibular.uerj.br/artigo/artigo-pdf.php?seq_artigo=44>. Acesso em: $<20 / 01 / 2018>$.

UNIVERSIDADE FEDERAL DO RIO DE JANEIRO. Regimento do fórum UFRJ acessível e inclusiva. Rio de Janeiro, 2017. Disponível em: $<$ https://ufrj.br/sites/default/files/documentos/2016/09/regimento_concluido_2.pdf $>$. Acesso em: $\langle 12 / 06 / 2018>$.

Recebido em: 25/10/2017

Aceito em: 22/01/2018 